\title{
Evaluation of a Smartphone-based Student Response System for Providing High Quality Real-time Responses in a Distributed Classroom
}

\author{
Séamus McLoone ${ }^{1}$, Simon O'Keeffe ${ }^{1}$, Rudi Villing ${ }^{1}$ and Connor Brennan ${ }^{2}$ \\ ${ }^{I}$ The Callan Institute, \\ Department of Electronic Engineering, \\ NUI Maynooth Co. Kildare, Ireland \\ ${ }^{2}$ School of Electronic Engineering, \\ DCU, Dublin, Ireland \\ Email: seamus.mcloone@eeng.nuim.ie \\ Email: cbrennan@dcu.ie
}

\begin{abstract}
Student response systems (SRSs) have increased in popularity over the past decade, with their use in the classroom steadily increasing. They offer several important pedagogical benefits including improved student learning, increased student interaction, improved student attendance, better student satisfaction and the creation of an enjoyable learning atmosphere. Most notably, they provide a mechanism for anonymous submission, thus allowing students to respond without the fear of being identified. While several different types of such systems exist, most of them have several drawbacks associated with them. These include (i) limited input capabilities, as the SRSs typically only offer a multiple-choice option and/or a numerical and textual based submission, (ii) practical issues in terms of portability, as the lecturer is typically responsible for having to carry a large number of devices to the classroom, and (iii) lack of suitability for distributed classrooms, as most SRSs employ short range infra-red communication that restricts their use to the physical classroom. In this paper, we propose the use of a smart phone based student response system that overcomes these issues. This new system builds upon existing work by the authors, whereby a tablet-based system was developed for in-class use. This paper has two key aspects - the first relates to modifications to the existing tablet-based solution and the second is the evaluation of the new system in a distributed classroom setting. Details of the modifications and the results of the evaluation are both presented within.
\end{abstract}

Keywords - Student Response Systems, Technology in the Classroom, Smart Devices, Smart Phones

\section{INTRODUCTION}

Student interaction and engagement are important aspects of any good classroom environment. As teachers, we are all too aware of the dreaded silence that often follows a question posed to a classroom of students. The larger the class, the more timid students become and the less likely they are to ask or respond to questions, in the fear of embarrassing themselves. Nevertheless, the mere presence of students in the classroom offers some sort of instant feedback to the teacher. Blank or puzzled looks is a good indicator that the taught material is too complex or not being clearly understood.

Now, consider the case of a distributed classroom, whereby a teacher could be interacting in real-time with students from different universities at a given instance in time. For example, the lecturer may be located in front of a PC in an office in Maynooth, while lecturing to one group of students based in a physical classroom in Dublin, another group of students based in a classroom in Maynooth and yet other students joining in from the comforts of their own home. Student responses and feedback in this case are essential, otherwise the learning and teaching experience is a potentially uninspiring and dull one for all involved. Without the proper setup, and the use of webcams for example, the lecturer does not even have the benefit of puzzled looks to work with. If students have individual access to the virtual classroom then some may choose to respond through the medium of software, such as that of chat windows. However, for larger groups of students, resources are not always available to facilitate individualised connections and a compromise 
solution is to have students grouped together in a classroom, viewing the lecturer's class material on an overhead screen. The communication in this scenario is typically one-way.

Student response systems (SRSs) have been proposed as a means of improving student interaction in the classroom, with high degrees of success. These systems exist in educational literature under many different guises including audience response systems, classroom response systems, voting machines and Clickers [1-5]. All such systems are very similar in nature [5, 6], consisting of a transmitter device for the students to communicate their responses, a receiver device for the lecturer to collate this information and software that interprets the responses and presents them in a convenient and useful form. An example of one such system is presented in Fig. 1 below:

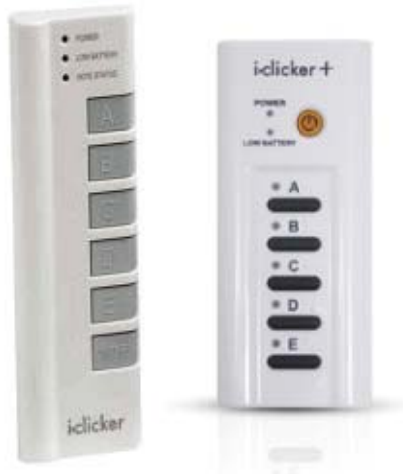

Fig. 1: The iClicker keypad*

The literature clearly illustrates the many pedagogical benefits and educational uses of student response systems including improved student learning, increased student interaction, increased student preparation for classes, increased student attendance, increased student satisfaction and the creation of an enjoyable learning atmosphere [5, 710]. In addition, SRSs can be used for student assessment and obtaining anonymous student feedback $[7,11]$.

However, while several different types of SRSs exist, they currently have several drawbacks:

- Primarily, they have limited input capabilities. Most devices, such as the one shown in Fig. 1, only allow for a multiple-choice input, whereby students select from a set of possible answers to a posed question. Some devices do allow for a numeric or text-based submission. However, most of these devices do not allow for a more generic freeform input, such as a mathematical equation, a circuit diagram or a graphical method. This lack of freeform input is of key concern in the Engineering and Science disciplines where such information is fundamental to the student learning experience. For example, consider processes such as logic minimisation using Karnaugh Maps, circuit design, mathematical analysis or software debugging. It is important that students can carry out these fundamental processes and, if we are to capture immediate feedback on the students' grasp of such methodology, then it is necessary for a SRS to facilitate freeform input.

- There is a practical issue in terms of portability. Currently, it is common practice for the lecturer to have to bring to the classroom a large number clickers and an associated base unit along with the necessary material for the lecture itself. This is neither practical nor convenient. An alternative is to have the students take individual responsibility for a clicker, but this is not ideal either, as individual units may get lost and students may not take them to class. Furthermore, the units can only be used by that particular student and not rotated among other classes and modules at the same time.

- Existing response systems typically employ short range infra-red or radio communication to link the transmitting student input devices to the receiving base unit. Hence, such systems are limited to the physical classroom in which they are employed. In other words, the system is not suitable to a distributed classroom scenario.

It should be noted that the iClicker solution has recently developed a supporting app for use on smart devices, called the iClickerGO. This app was designed to allow smart phones and tablets to be used as alternative Clicker transmitters. Thus, while this aids with the practical issue of portability, it does not cater for freeform input and, to the best knowledge of the authors, has not been evaluated in a distributed setting.

In this paper, we propose the use of a smart phone based SRS that allows for freeform input in the form of sketching. In particular we employ an improved version of an existing solution that we developed for use on tablets [12]. In this case, the original system was developed for use on large screen tablets (typically 10 inch). Here, we cater for the much smaller screens of smart phones.

To date, we have focused only on smart phones that employ the Android operating system. The smart phone SRS consists of a student sketch application, a lecturer 'view and mark-up' application and a cloud-based service for co-ordinating between these two applications. 
The new smart phone based SRS is evaluated in a distributed classroom setting involving a class of Electronic Engineering students at NUIM and their counterparts at Dublin City University DCU. Initial feedback from both sets of students is very positive.

The rest of the paper is structured as follows. Section II outlines the key operational features of the original tablet-based student response system. Important improvements to this system are outlined in section III, while section IV presents the results of the distributed classroom evaluation study. The paper concludes with some ideas for future work in section $\mathrm{V}$.

\section{THE TABLET-BASED SRS}

Readers are referred to [12] for a comprehensive overview of the original tablet-based SRS. However, the main features of this system are presented here for the convenience of the reader. The system has three key elements. These are the student application (or student app), the lecturer application (or lecturer app) and the central server.

The central server is the hidden component of the system from a user's point of view. It co-ordinates the exchange of responses between the student and the lecturer and any marked-up edits back to the students. For this system, we use the Google App Engine cloud based service to perform the relevant exchange of response. In doing so, it allows us to work with non-Android systems in the future. In other words, suitable student and lecturer applications could be written for other devices, such as the iPad and the iPhone, which would seamlessly integrate with our current student response system.

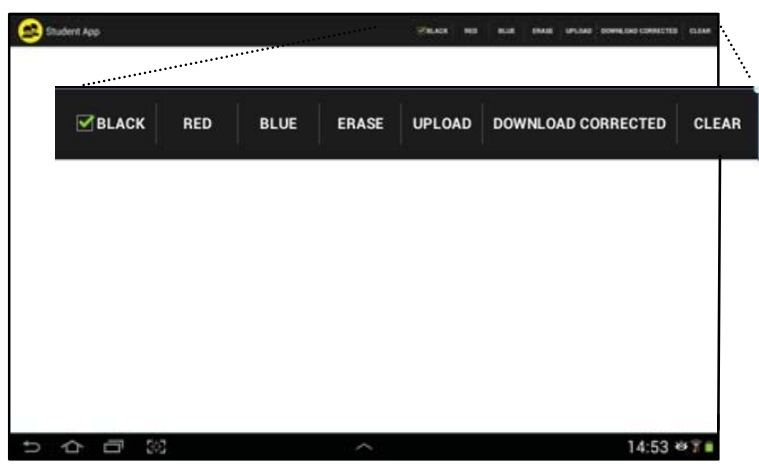

Fig. 2: Initial screen on opening student application, with menu options enlarged for ease of viewing

The student app allows for basic sketching capabilities. When a student selects the student app on their tablet, they are initially presented with a blank canvas with various sketch options as shown in Fig. 2 above. The menu options have been enlarged for viewing convenience. Students have the option of sketching in three different colours.
They can erase any errors made or can clear the sketch completely. On completion, the student can submit their sketch to the cloud server. The student's submission is typically in response to a question posed by the lecturer during class.

The main function of the lecture app is to view the submissions from the students in a quick and easy fashion. When the lecturer app is opened, the lecturer can download the images submitted on the server by the students. Images are downloaded in a grid format, as illustrated in Fig. 3 below.

DOWNLOAD ALL DOWNLOAD MOST RECENT DELETE ALL

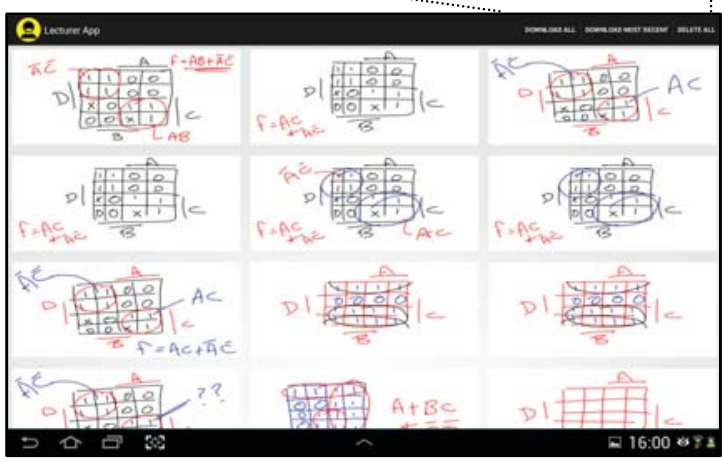

Fig. 3: Screenshot of downloaded images on lecturer's device, with menu options enlarged for ease of viewing
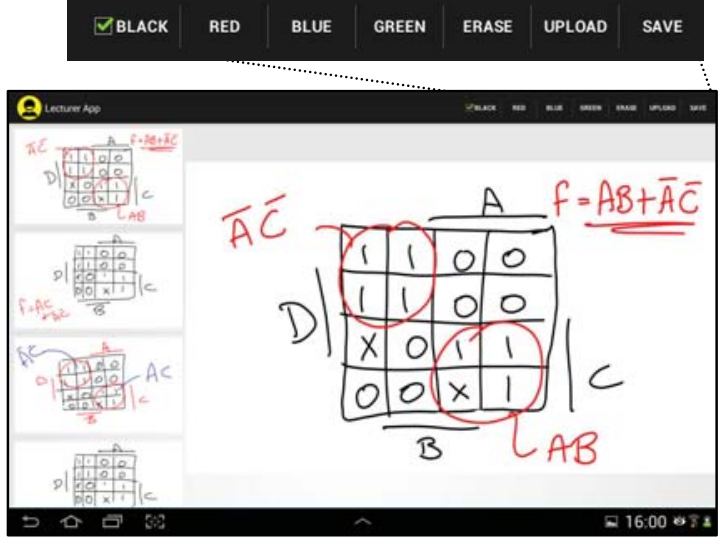

Fig. 4: Lecturer app in 'marking' mode, with menu options enlarged for ease of viewing

By selecting one of the images in the grid, the view then changes to a two-panel window, as shown in Fig. 4. Here, all the images are still easily accessible on the left panel, while the selected image is shown in the main panel. The menu options have also changed to allow the lecturer to mark the image and add comments, etc. The lecturer can upload the edited image back to the server so that the student can download it at a later stage. 


\section{THE NEW SMARTPHONE-BASED SRS}

The tablet-based SRS outlined in the previous section was very much a beta version, with limited functionality. Furthermore it was developed for viewing on the large screens associated with tablets - as such this system was not ideal for direct deployment on smart phones.

We now outline three significant improvements to the tablet-based SRS. Although some of these improvements were made with a smart phone in mind, they are still valid for the tablet interface.

Firstly, the original system could only be used by a single class of students at any given time, as all students shared the same database for submissions. The updated SRS now contains a user log in screen for both the student and lecturer applications, similar to the one in Fig. 5 below. Here, the lecture first creates a session on their device, by entering a suitable session name. The name of this session is them communicated to the students (verbally or via email for example) so that they can $\log$ on to the correct module session. Now, the students and lecturer for this session have their own dedicated database for submissions. This feature allows the new version of the SRS to be used simultaneously by different classes.

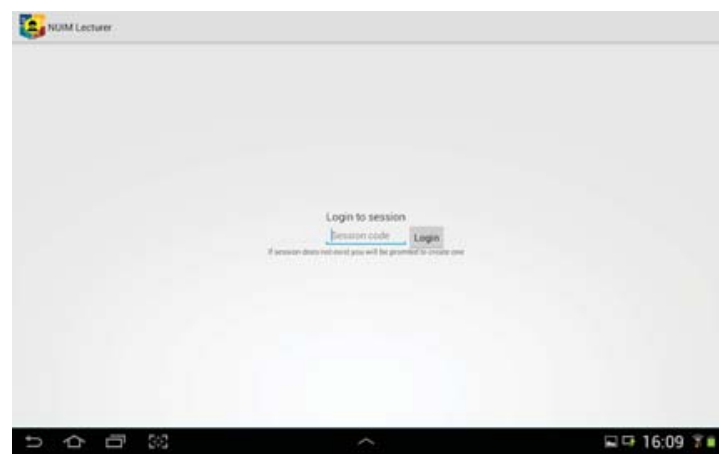

Fig. 5: New session login screen

The second new feature involves using templates. The lecturer can prepare and store template sketches in advance of a class to be ready for use during class. Templates have multiple uses - they can be used as the basis for predetermined questions for class. Alternatively, they can be used as an outline framework for common repetitive processes such as using Karnaugh Maps for logic minimisation. Here, it is useful to have a template outline of the Karnaugh map to send to students. This is particularly beneficial for users of the phone-based SRS as they don't need to worry about sketching a relatively neat Karnaugh Map on their small screen of the phone.
To use a template, the lecturer simply selects the appropriate template and makes it available to all the students within the same module session. Fig 6 shows four possible templates that have been created and stored. Note the first template is simply a blank canvas. This caters for questions that the lecturer may think of during the live session.

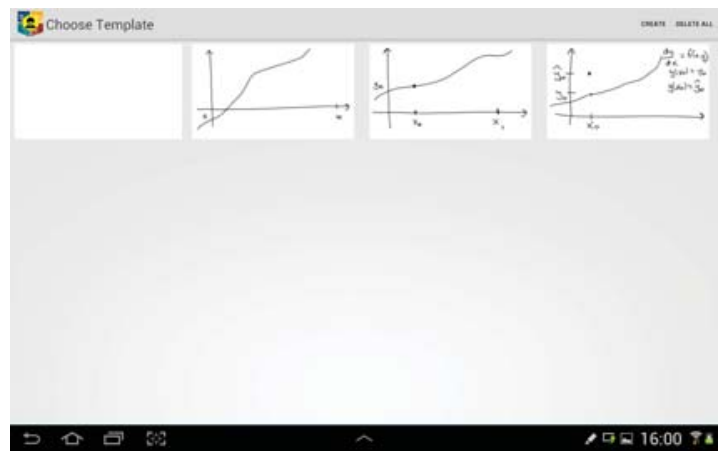

Fig. 6: Set of templates ready for use - lecturer app

Once a student logs in into a new session, they are presented with the option of starting a new question. Selecting this option will present the template, chosen by the lecturer, to the student. They can then add to it, in order to answer a given question, using their own sketch options. On completion, they can submit their work to the cloud server database which, in turn, is sent to the lecturer's device for viewing. The lecturer can view and edit the submissions in the same manner as described for the tablet-based SRS in section II of this paper.
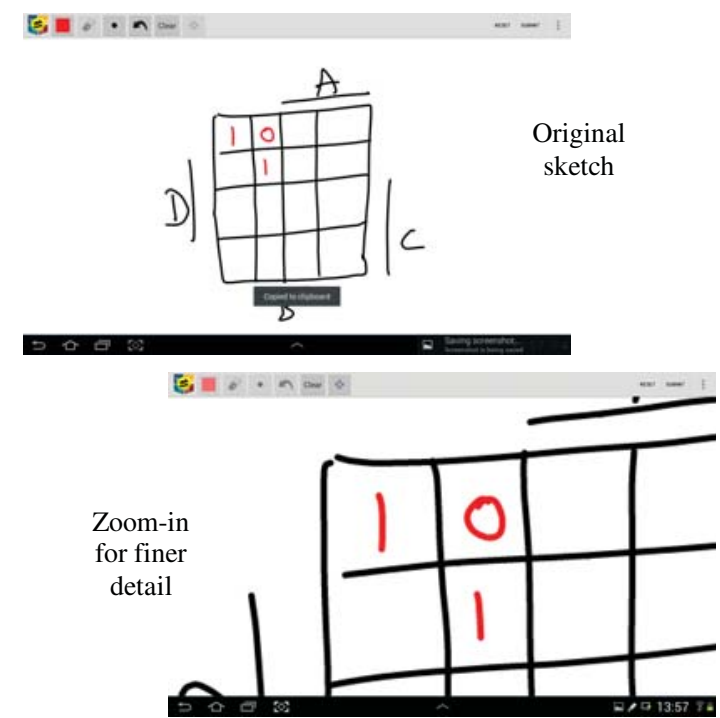

Fig. 7: The zoom-in zoom-out functionality of the new SRS - catering for the small screens of smart phones

The third and final important system improvement is to include a zoom-in zoom-out function on the student sketch app. In the original SRS, the screen was fixed, with no zoom options. This was more 
than adequate for use on tablets but very limiting for use on the phones. On the new system, students can now zoom in on their sketch to include more detail, if necessary. Fig. 7 shows an example of the zoomin functionality in operation.

\section{DistRIBUTED ClassRoOM EVALUATION}

The new smartphone-based SRS was used and evaluated by students of the Year 3 Computation and Simulation module, which was delivered in a distributed classroom setup as follows. The module was hosted by the School of Electronic Engineering in DCU and was taken by students from both DCU and NUIM. The lecturer of the module was based in the DCU classroom along with the DCU students while the NUIM students were based in a classroom in NUIM, with individual pc access. Big Blue Button (http://bigbluebutton.org/) was used as the virtual classroom software.

There were about 40 DCU students and 14 NUIM students, comprising mostly of male students. Overall the combined class included a small number of mature students and a cohort of approximately 17 international students.

The evaluation of the SRS took place on two different lecture occasions over the duration of the module (in this case the module was completed in a 5 week period from February - March 2014).

Both DCU and NUIM students were presented with different questions at various times throughout the lectures and the responses from their individually owned smart phones were collated and viewed in real-time on the lecturer's tablet. The questions related to material covered in the class and required students to answer with suitable sketches. For example, one such question required students to graphically depict how the Euler method for solving ODEs would approximate the actual solution function, which was supplied in the template as a reference. Some sample student responses are shown in Fig. 8.

Both sets of students were surveyed using paper questionnaires for their views of the new phonebased SRS. Table 1 shows the average and standard deviation of the ratings given by the students' for a range of statements, as shown. Students were asked to rate each statement on a scale of 1 (strongly disagree) to 5 (strongly agree).

Unfortunately, only 12 survey responses were collected (6 from DCU and 6 from NUIM), representing approximately $22 \%$ of the class. This low number is directly attributed to the fact that only a small percentage of students had smart phones and, in addition, the SRS currently only operates on phones using the Android operating system. Thus iPhone owners were unable to participate in this evaluation. Nevertheless, the results obtained provide useful insight to the effectiveness of the phone based SRS. It is also worth stating that there was no notable difference in the responses of the NUIM (remote) and DCU (nonremote) students.

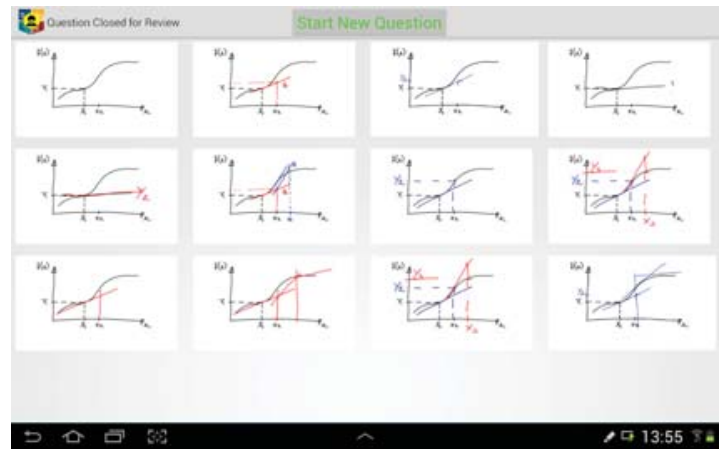

Fig. 8: Sample student responses from evaluation study

Table 1 -SRS evaluation results. 1 to 5 represents strongly disagree, disagree, not sure, agree and strongly agree respectively.

\begin{tabular}{|c|c|c|}
\hline Statement & $\begin{array}{c}\text { Average } \\
\text { rating (1-5) }\end{array}$ & $\begin{array}{l}\text { Std. } \\
\text { dev. }\end{array}$ \\
\hline I found the app easy to use & 4.0 & 0.85 \\
\hline $\begin{array}{l}\text { I felt the app was quick and } \\
\text { responsive }\end{array}$ & 4.0 & 0.43 \\
\hline $\begin{array}{c}\text { The app performed as } \\
\text { expected }\end{array}$ & 3.9 & 0.67 \\
\hline $\begin{array}{l}\text { The app provided a good } \\
\text { way to interact in class }\end{array}$ & 4.1 & 0.29 \\
\hline $\begin{array}{c}\text { The app provided a good } \\
\text { way to give } \\
\text { feedback/responses }\end{array}$ & 4.2 & 0.58 \\
\hline $\begin{array}{l}\text { The flexibility of providing } \\
\text { a sketch is really useful }\end{array}$ & 4.1 & 0.67 \\
\hline $\begin{array}{l}\text { The use of the response } \\
\text { system makes my learning } \\
\text { more enjoyable }\end{array}$ & 4.1 & 0.79 \\
\hline $\begin{array}{l}\text { I was motivated to respond } \\
\text { to the lecturer's questions } \\
\text { using this system }\end{array}$ & 4.2 & 0.60 \\
\hline $\begin{array}{l}\text { I would like to use this } \\
\text { response system again }\end{array}$ & 4.0 & 0.77 \\
\hline
\end{tabular}

From Table 1, we see that the students found the application easy to use, with no prompting required. They liked the overall system and felt it made their learning experience more enjoyable and, moreover, wanted to use the system in future classes. More importantly, students found the idea of responding with sketches as useful, flexible and a good means of giving feedback and interacting in class. 
In terms of additional feedback obtained, via comment boxes, some students noted that the system was "a nice way of learning" and "makes lectures more enjoyable". Most of the students stated that they liked the fact that responses were anonymous, expressing that they were no longer afraid of giving wrong answers, clearly supporting the research findings in [11].

The Computation and Simulation lecturer was also asked for his opinion on the smartphone-based SRS, as he had no knowledge of this system prior to using it for the first time in the class. His first impression was that the response system was extremely beneficial, well worth using and appeared to capture the interest of his students almost instantly. He found it particularly useful for breaking up the lecture which, in this case, alternated between 2 and 3 hour sessions. He noted that it worked well in the distributed classroom setting and that there were no apparent issues with delayed responses, etc.

By way of improvement, the lecturer suggested that it would be nice to have the ability to create templates with perfect shapes, i.e. a proper square or circle as opposed to one sketched by hand. He also made an interesting observation on the use of the SRS. He found that it was useful to, at some point during the session, allow students to draw and submit a random sketch (i.e. whatever they felt like drawing). This one-off dispensation seemed to satisfy any temptation they may have to misbehave and focused their minds on properly responding to actual questions thereafter.

\section{CONCLUSIONS \& FUTURE WORK}

This paper has presented a smartphone-based student response system that has freeform input capabilities. The current system has been developed for phones with the Android operating system.

Evaluation results show that students are strongly in favour of the proposed system. They find the system easy to use, like the flexibility that a sketch input offers and appreciate the fact that it offers anonymity to the student.

The evaluation also revealed that the SRS can easily be used in a distributed setting whereby students are physically located in two different classrooms whilst sharing the same module.

Future work involves developing a student app and a lecturer app for devices supporting alternative operating systems, such as iPhones and iPads.

\section{ACKNOWLEDGEMENTS}

We would like to thank the Centre for Teaching and Learning, NUIM and the $3 \mathrm{U}$ NSTEP scheme for providing the research funding for this project. We would also like to thank all the students and staff who partook in the surveys of our SRS.

\section{REFERENCES}

[1] C. Fies and J. Marshall, "Classroom response systems: a review of the literature," Journal of Science Education and Technology, 15(1), 101-109, 2006.

[2] R.G. Miller, B. H. Ashar and K. J. Getz, "Evaluation of an audience response system for the continuing education of health professionals," Journal of Continuing Education in the Health Professions, 23, 109-115, 2003.

[3] J. Roschelle, W. R. Penuel and A. L. Abrahamson, "Classroom response and communications systems; research review and theory," In Annual Meeting of the American Educational Research Association, San Diego, CA, 1-8, 2004.

[4] N. W. Reay, L. Bao, L. Pengfei, R. Warnakulasooriya and G. Baugh, "Towards an effective use of voting machines in physics lectures," American Journal of Physics, 73, 554-558, 2005.

[5] M. Barber and D. Njus, "Clicker evolution: seeking intelligent design." The American Society for Cell Biology, 6, 1-20, 2007.

[6] R. A. Bunstein and L. M. Lederman, "Comparison of different commercial wireless keypad systems," The Physics Teacher, 41, 272-275, 2003.

[7] J. E. Caldwell, "Clickers in the large classroom: current research and best-practice tips," Life Sciences Education, 6, 9-20, 2007.

[8] C. Moredich and E. Moore, "Engaging student through the use of classroom response systems," Nurse Educator, 32(3), 113-116, 2007.

[9] R. Auras and L. Bix, "Wake up! The effectiveness of a student response system in large packaging classes," Packaging Technology and Science, 20(3), 183-195, 2007.

[10] D. J. Skiba, "Got large lecture hall classes? Use clickers," Nursing Edu. Perspectives, 27(5), 278-280, 2006.

[11] C. R. Graham, T. R. Tripp, L. Seawright and G. L. Joeckel, "Empowering or compelling reluctant participators using audience response systems," Sage Publications, 8(3), 233-258.

[12] S. C. McLoone, S. O'Keeffe and R. Villing, "Design, implementation and evaluation of a tablet-based student response system for an engineering classroom," Proc. IET Irish Signals and Systems Conference, LYIT Letterkenny, June 20-21, 2013 